\title{
Management of traumatic extremity arterial injuries in a tertiary care center: A report with 197 cases
}

\author{
Helin El Kılıç (D), İsmail Koramaz (D) \\ Department of Cardiovascular Surgery, Health Science University, Şişli Hamidiye Etfal Training and Research Hospital, Istanbul, Turkey
}

\begin{abstract}
Objectives: This study aims to analyze patients' characteristics, treatments applied, and treatment outcomes following traumatic extremity arterial injuries (TEAIs) in a tertiary care center.

Patients and methods: A total of 197 patients (185 males, 12 females; mean age: $32.5 \pm 10.1$ years; range, 13 to 67 years) who underwent emergency operation due to a TEAI in our center between January 2013 and March 2020 were retrospectively analyzed. Data including sex, age, body mass index (BMI), admission time to hospital, side of injury, injured artery or arteries, cause of injury, and associated injuries were noted. Treatments applied, length of hospital and intensive care unit (ICU) stay, and the mortality rate were recorded.

Results: Penetrating injuries and gunshot wounds were found in 81 (41.1\%) and 68 (34.5\%) patients, respectively. Bone fractures and nerve injuries were accompanied by a TEAI in $38(19.3 \%)$ and $11(5.6 \%)$ patients. Superficial femoral artery (SFA) was the most frequently injured artery (56\%). Bypass with saphenous vein was the most utilized management modality in $89(45.2 \%)$ patients, while primary repair was performed in $64(32.5 \%)$ patients. Infection developed in nine (4.6\%) patients. Fasciotomy was required due to compartment syndrome in $17(8.6 \%)$ patients. Extremity amputation was performed in three (1.5\%) patients and mortality was seen in three (1.5\%) patients.
\end{abstract}

Conclusion: Our study results suggest that penetrating traumas are the most common cause of TEAI, and that SFA is the most commonly injured artery. Primary repair and bypass with saphenous vein are the most utilized techniques in the management of TEAIs.

Keywords: Amputation, extremity artery injury, fasciotomy, primary repair, saphenous vein graft, vascular injury.

Traumatic extremity arterial injuries (TEAIs) are rare entities due to the elastic nature of vessels and presence of protective tissues around them. Previous reports have demonstrated that TEAI is seen in 2 to $3 \%$ of all traumatic injuries. ${ }^{[1]}$ However, Khan et al. $^{[2]}$ reported that the incidence of TEAI was relatively higher in developing countries due to more frequent traffic accidents, violent crimes, and industrial injuries. Although relatively rare, TEAIs may be associated with serious consequences, including function loss, extremity amputation, and even death. ${ }^{[3]}$

Early diagnosis, systemic approach, and rapid intervention are critical to prevent morbidity and mortality due to TEAIs. Feliciano et al. ${ }^{[4]}$ reported that examination of the peripheral artery was essential for all trauma patients, even in those with stable hemodynamic status. Additionally, appropriate imaging modalities such as Doppler ultrasonography, computed tomography angiography (CTA), or conventional angiography should be performed for diagnosis and appropriate treatment decisions. ${ }^{[5]}$ In patients with a unstable hemodynamic condition, external pressure and/or tourniquet should be applied before the emergency intervention. In cases with unstoppable and/or life-threatening bleeding, the emergency operation room treatment options are primary repair, ligation of vessel, autologous graft

Received: March 21, 2021 Accepted: May 25, 2021 Published online: June 23, 2021

Correspondence: Helin El Kılıç, MD. SBÜ Şişli Hamidiye Etfal Eğitim ve Araştırma Hastanesi Kalp ve Damar Cerrahisi Kliniği, 34371 Şişli, İstanbul, Türkiye. e-mail: helin_el@hotmail.com 
interposition or synthetic graft placement and, in some cases, amputation of extremity. ${ }^{[6]}$

Although previous studies have investigated patients' characteristics, treatment options and outcomes following TEAIs, there are conflicting results and no consensus on standardization of procedures in the literature. In the present study, we aimed to analyze patients' characteristics, treatments applied, and treatment outcomes following TEAI in a tertiary care center and to help to fill the gap in the literature on this subject.

\section{PATIENTS AND METHODS}

This single-center, retrospective study was conducted at Health Science University, Şişli Hamidiye Etfal Training and Research Hospital, Department of Cardiovascular Surgery between January 2013 and March 2020. A total of 197 patients (185 males, 12 females; mean age: $32.5 \pm 10.1$ years; range, 13 to 67 years) who underwent emergency operation due to a TEAI in our center were retrospectively analyzed. Preoperative data including age, sex, body mass index, arrival time to hospital, injured limb, side, cause of injury, and presence of bone and nerve injuries were recorded. Only the patients who had a TEAI and salvageable extremity with or without orthopedic, neurological and/or soft tissue injuries were included in this study. Those who required urgent attention to abdomen and/or head injuries, had extremities with no signs of viability or a non-salvageable extremity due to TEAI, and had a Glasgow Coma Score of $\leq 3$ were excluded. Other exclusion criteria were blunt traumas, including traffic and work accidents, bomb blast injuries, and falls from height. A written informed consent was obtained from each patient. The study protocol was approved by the Health Science University, Şişli Hamidiye Etfal Research and Training Hospital Ethics Committee (02.02.2021/3118). The study was conducted in accordance with the principles of the Declaration of Helsinki.

All patients admitted to the emergency service with the suspicion of a TEAI were evaluated according to the American College of Surgeons Guidelines for Advanced Trauma and Life Support. ${ }^{[7]}$ The diagnosis of TEAI was made based on physical examination and/or imaging modalities (Doppler ultrasonography, CTA, or conventional angiography). The followings were considered the signs of a TEAI: presence of active bleeding, expanding hematoma, cold and pale extremity, absent or weak artery pulses and pronounced neurological deficit. In patients with a stable condition, the imaging modalities were used to identify the location and severity of the injury and to tailor the treatment plan. Patients in critical condition with impaired vital signs were immediately operated without any further diagnostic evaluation.

In all patients, operations were performed under general anesthesia or dissociative anesthesia. In cases of bone fracture, if the patient was hemodynamically instable, vascular surgery was performed first; otherwise, bone fixation was initially applied. Any nerve injuries detected were repaired by a plastic surgeon. If possible, primary repair of artery was performed, but if not, one of the following treatment modalities was performed: coil embolization, arterial ligation, arterial bypass with a prosthetic graft or saphenous vein, thrombectomy or extremity amputation. Prosthetic graft was carried out only in patients with multiple artery injuries or where there was not sufficient time for saphenous vein harvesting. Fasciotomy was only performed in the following cases: suspected or proven compartment syndrome, ischemia of at least $6 \mathrm{~h}$, and for any neurological deficit. In patients with severe soft tissue injury, all dead tissues and foreign bodies were removed, and the injury site was cleaned with isotonic saline solution. Operations were considered successful, if the extremity pulse returned. For all patients, antibiotic prophylaxis was given on Days 3 to 5 in the postoperative period. In patients with severe soft tissue loss and presence of infection, the antibiotic regimen was prolonged. Additionally, low-molecular-weight heparin was given for five to seven days in the postoperative period, and antiaggregant (acetylsalicylic acid or clopidogrel) treatment was continued for four weeks after surgery. The length of hospital and intensive care unit (ICU) stay, complications and mortality rate were recorded.

\section{Statistical analysis}

Statistical analysis was performed using the IBM SPSS version 21.0 software (IBM Corp., Armonk, NY, USA). Descriptive data were expressed in mean \pm standard deviation, median (min-max) or number and frequency.

\section{RESULTS}

The mean age and the mean BMI were $32.5 \pm 10.1$ years and $26.8 \pm 5.1 \mathrm{~kg} / \mathrm{m}^{2}$, respectively. Of the patients, 118 had upper extremity artery injuries, 64 had lower extremity artery injuries, and 15 had both upper and 


\begin{tabular}{|c|c|c|c|}
\hline & $\mathrm{n}$ & $\%$ & Mean $\pm S D$ \\
\hline Age (year) & & & $32.5 \pm 10.1$ \\
\hline \multicolumn{4}{|l|}{ Sex } \\
\hline Male & 185 & 94.0 & \\
\hline Body mass index $\left(\mathrm{kg} / \mathrm{m}^{2}\right)$ & & & $26.8 \pm 5.2$ \\
\hline Arrival time to the hospital (min) & & & $23.5 \pm 12.8$ \\
\hline \multicolumn{4}{|l|}{ Injured limb } \\
\hline Lower limb & 118 & 59.9 & \\
\hline Upper limb & 64 & 32.5 & \\
\hline Lower + upper limb & 15 & 7.6 & \\
\hline \multicolumn{4}{|l|}{ Side } \\
\hline Right & 94 & 47.7 & \\
\hline Left & 81 & 41.1 & \\
\hline Bilateral & 22 & 11.2 & \\
\hline \multicolumn{4}{|l|}{ Cause of injury } \\
\hline Penetrating injury & 81 & 41.1 & \\
\hline Gunshot wound & 68 & 34.5 & \\
\hline Blunt trauma & 48 & 24.4 & \\
\hline Number of patients receiving imaging & 132 & 67.0 & \\
\hline Bone fracture & 38 & 19.3 & \\
\hline Nerve injury & 11 & 5.6 & \\
\hline
\end{tabular}

SD: Standard deviation.

\begin{tabular}{lcc} 
Table 2. Location of arterial injuries $(\mathbf{n}=\mathbf{1 9 7})$ & & \\
\hline & $\mathrm{n}$ & $\%$ \\
\hline Axillary artery & 12 & 6.1 \\
Brachial artery & 38 & 19.3 \\
Common femoral artery & 9 & 4.6 \\
Deep femoral artery & 13 & 6.6 \\
Popliteal artery & 27 & 13.7 \\
Superficial femoral artery & 56 & 28.4 \\
Trifurcation arteries & 17 & 8.6 \\
Ulnar artery & 6 & 3.1 \\
Multiple arteries & 19 & 9.6 \\
\hline
\end{tabular}

lower extremity arterial injuries. Penetrating injuries and gunshot wounds were observed in 81 (41.1\%) and $68(34.5 \%)$ patients, respectively. Bone fracture and nerve injury were accompanied by TEAI in 38 (19.3\%) and 11 (5.6\%) patients, respectively. Baseline demographic and clinical characteristics of the patients are summarized in Table 1 .

In the present study, superficial femoral artery (SFA) was the most frequently injured artery in 53 (56\%) patients, followed by brachial artery (19.3\%) and popliteal artery (13.7\%). Other injured arteries were deep femoral artery (DFA) in 13, trifurcation arteries in 17 , axillary artery in 12 , common femoral

\section{Table 3. Treatment modalities ( $\mathrm{n}=197)$}

\begin{tabular}{lcc}
\hline & $\mathrm{n}$ & $\%$ \\
\hline Coil embolization & 2 & 1.0 \\
Ligation & 26 & 13.2 \\
Primary repair & 64 & 32.5 \\
Bypass with prosthetic graft & 6 & 3.0 \\
Bypass with saphenous vein & 89 & 45.2 \\
Thromboectomy & 7 & 3.6 \\
Amputation & 3 & 1.5 \\
\hline
\end{tabular}

Table 4. Complications and postoperative follow-up outcomes

\begin{tabular}{lccc}
\hline & $\mathrm{n}$ & $\%$ & Mean $\pm \mathrm{SD}$ \\
\hline Complications & 32 & 16.2 & \\
$\quad$ Infection & 9 & 4.6 & \\
$\quad$ Compartment syndrome & 17 & 8.6 & \\
$\quad$ Amputation & 3 & 1.5 & \\
$\quad$ Death & 3 & 1.5 & \\
Hospitalization period (days) & & & $16.7 \pm 11.8$ \\
Length of stay in the ICU (days) & & & $6.3 \pm 4.2$ \\
\hline SD: Standard deviation; ICU: Intensive care unit. & & &
\end{tabular}

artery (CFA) in nine, and ulnar artery in six patients. Multiple artery injuries occurred in 19 patients (Table 2).

Bypass with the saphenous vein was the most often utilized management modality in almost half of the patients ( $n=89,45.2 \%)$. Primary repair was performed in 64 (32.5\%), ligation in $26(13.2 \%)$, bypass with a prosthetic graft in six (3.0\%) and thrombectomy in seven (3.6\%), and coil embolization, in two (1.0\%) patients (Table 3 ).

In this study, the mean length of hospital stay was $16.7 \pm 11.8$ days and the mean length of ICU stay was $6.3 \pm 4.2$ days. Infection developed in nine patients (4.6\%) and fasciotomy was required due to compartment syndrome in 17 (8.6\%) patients. Extremity amputation was performed in three $(1.5 \%)$ patients and mortality was seen in three (1.5\%) patients (Table 4).

\section{DISCUSSION}

Trauma is still one of the major causes of death, and extremity arterial vascular injuries significantly increase the morbidity and mortality rates. Although TEAI is rare entity, Gurkan et al. ${ }^{[7]}$ reported an increase in vascular injuries over the past decade. In a study by Khan et al., ${ }^{[2]}$ the nature of TEAI was found to vary between countries, and treatment approaches varied between the Western and Eastern hemispheres. 
Thus, the present study conducted in a tertiary care center of a developing country and investigating characteristics and treatment outcomes of TEAIs has the potential to contribute to the literature.

Arterial injuries have many different causes including penetrating traumas, gunshot injuries, and blunt traumas. Penetrating and gunshot injuries have been shown to be the most common causes of extremity vascular injuries in many studies. Ünlü et al. ${ }^{[8]}$ reported that penetrating traumas and gunshot injuries were the most common causes of upper extremity vascular injuries. Becit et al. ${ }^{[9]}$ found penetrating and gunshot injuries to be the cause of $80.2 \%$ of vascular injuries. In contrast, for lower extremity vascular injuries, Sciarretta et al. ${ }^{[10]}$ found blunt traumas to be the most common cause. Consistent with the literature, in our series, penetrating and gunshot injuries were found to be the most common causes.

The type of vessel injured plays an important role in the treatment decision and in determining the patient's chances of survival. Halic1 et al. ${ }^{[1]}$ showed that radial artery and popliteal arteries were most commonly injured arteries in the upper and lower extremity, respectively. However, Khan et al. ${ }^{[2]}$ found popliteal artery to be the most commonly injured lower extremity artery, while they found brachial artery was the most common injured in the upper extremity. We believe that three factors may account for the differences in the most frequently injured arteries between the studies: the country, the data collection procedures implemented, and the definition of anatomical features. In the present study, SFA and brachial artery were found to be the most commonly injured.

Management of TEAIs requires an appropriate surgical intervention under emergency conditions. In a study analyzing lower extremity arterial injuries, repair with the saphenous vein graft (SFG) was the most common technique. ${ }^{[10]}$ Ekim and Tuncer ${ }^{[12]}$ performed end-to-end anastomosis in 28 of 49 cases in the management of brachial artery injuries. This technique was also the most preferred treatment option in the management of traumatic vascular injuries by Halic1 et a1. ${ }^{[1]}$ In parallel with the literature, in present study, SFG and primary repair were the most frequently performed methods for TEAI.

Surgeons should be aware of the dangers of non-vascular pathologies accompanying arterial injuries. Bishara et al. ${ }^{[13]}$ reported that bone dislocations and fractures were commonly associated with vascular injuries, and increased the mortality rate by $10 \%$. In another study, extremity bone pathologies increased the amputation rate by up to $40 \% \cdot{ }^{[14]}$ Ekim et al. ${ }^{[12]}$ also found that, of 49 patients diagnosed with vascular injuries, 13 had orthopedic pathologies and 11 had nerve injuries. In the present study, $19.3 \%$ of the patients had a bone fracture and $5.6 \%$ had a nerve injury.

Compartment syndrome is a condition in which the increased pressure in the anatomical compartments of the body results in insufficient blood flow to tissue. ${ }^{[15]}$ Sciarretta et al. ${ }^{[10]}$ performed fasciotomy in 19 of $26(73.1 \%)$ patients with blunt trauma and 16 of 21 (76.2\%) patients with penetrating trauma. ${ }^{[10]}$ Fasciotomy was not a routine procedure in our study and was only performed in $8.6 \%$ of the patients. A possible explanation for this difference is that fasciotomy is usually applied only to the cases with prolonged extremity ischemia and, in the present study, the mean patient arrival time to the hospital was only $23.5 \pm 12.8 \mathrm{~min}$.

Amputation and death are most undesirable results of TEAI, and previous studies have shown varying rates for these outcomes. Burma et al. ${ }^{[16]}$ found that, following peripheral vascular injuries, the rates for amputation and death ranged from $1-10 \%$ to $1-5 \%$, respectively. In another study analyzing the data of 123 patients with vascular injuries, Salimi et al. ${ }^{[17]}$ found $11.4 \%$ amputation rate and $4 \%$ mortality rate. In contrast, Becit et al. ${ }^{[9]}$ reported amputation and death rates as $3.9 \%$ and $6.1 \%$, respectively. Additionally, Akça ${ }^{[18]}$ reported 8.3\% amputation rate following war-related injuries, whereas Hanedan et al. ${ }^{[19]}$ performed leg amputation in two of 28 patients in civil war-related injuries. In the present study, there were three extremity amputations (1.5\%) and three deaths (1.5\%). We found our amputation rates to be lower than other studies, which may be due to the fact that other studies particularly examined war injuries.

Nonetheless, there are some limitations to this study. First, it has a retrospective nature with a relatively small sample size. Second, operations were performed by a single cardiovascular surgery team, but by different cardiovascular surgeons. This may have influenced treatment decision and outcomes; however, all surgeons completed standardized education in the management of TEAIs. Third, patients' initial hemodynamic parameters at the time of admission, patients' life quality, and cost-efficacy analysis of the procedures were not considered in the present study, 
but may be the focus of further studies. Forth, we focused characteristics, management, and postoperative outcomes of TEAI, while long-term outcomes were beyond the scope of the study. Finally, we only investigated the cardiovascular aspect of TEAI due to the lack of data and we believe that further studies evaluating the multidisciplinary approach on TEAI would clarify this issue.

In conclusion, our study results suggest that penetrating traumas are the most common cause of TEAIs, and that SFA and brachial arteries are the most commonly injured arteries. Additionally, primary repair and bypass with the saphenous vein are the most utilized techniques with low amputation and complication rates in specialized centers implementing systemic approach, early diagnosis and treatment with advanced diagnostic tools. Further multi-center studies including the secondary care centers with reliable data could also identify the differences between centers and emerge appropriate management modality in these patients.

\section{Declaration of conflicting interests}

The authors declared no conflicts of interest with respect to the authorship and/or publication of this article.

\section{Funding}

The authors received no financial support for the research and/or authorship of this article.

\section{REFERENCES}

1. Perkins ZB, De'Ath HD, Aylwin C, Brohi K, Walsh M, Tai NR. Epidemiology and outcome of vascular trauma at a British Major Trauma Centre. Eur J Vasc Endovasc Surg 2012;44:203-9.

2. Khan FH, Yousuf KM, Bagwani AR. Vascular injuries of the extremities are a major challenge in a third world country. J Trauma Manag Outcomes 2015;9:5.

3. Franz RW, Shah KJ, Halaharvi D, Franz ET, Hartman JF, Wright ML. A 5-year review of management of lower extremity arterial injuries at an urban level I trauma center. J Vasc Surg 2011;53:1604-10.

4. Feliciano DV, Moore FA, Moore EE, West MA, Davis JW, Cocanour CS, et al. Evaluation and management of peripheral vascular injury. Part 1. Western Trauma Association/critical decisions in trauma. J Trauma 2011;70:1551-6.
5. Fox N, Rajani RR, Bokhari F, Chiu WC, Kerwin A, Seamon $\mathrm{MJ}$, et al. Evaluation and management of penetrating lower extremity arterial trauma: An Eastern Association for the Surgery of Trauma practice management guideline. J Trauma Acute Care Surg 2012;73(5 Suppl 4):S315-20.

6. Topal AE, Eren MN, Celik Y. Lower extremity arterial injuries over a six-year period: Outcomes, risk factors, and management. Vasc Health Risk Manag 2010;6:1103-10.

7. Gürkan S, Gür Ö, Hüseyin S, Yüksel V, Ünal S, Turan E. Periferik damar yaralanmaları: 10 yıllık deneyim. Turk J Vasc Surg 2012;21:34-7.

8. Ünlü Y, Vural Ü, Özyazıcıŏ̆lu A, Ceviz M, Karapolat S, Koçak H. Upper extremity vascular injuries (the evaluation of 98 cases). Turk Gogus Kalp Dama 1998;6:318-22.

9. Becit N, Ateş A, Özyazıcıŏlu A, Ünlü Y, Balcı AY, Ceviz M. Periferik arter yaralanmalarında değerlendirme ve cerrahi tedavi. Turk Gogus Kalp Dama 2000;8:540-4.

10. Sciarretta JD, Macedo FI, Otero CA, Figueroa JN, Pizano LR, Namias N. Management of traumatic popliteal vascular injuries in a level I trauma center: A 6-year experience. Int J Surg 2015;18:136-41.

11. Halıcı Ü, Karal İH, Ağırbaş H, Kanca A. Our experiences with the surgical repair of traumatic vascular injuries. Turk J Vasc Surg 2020;29:145-51.

12. Ekim H, Tuncer M. Management of traumatic brachial artery injuries: A report on 49 patients. Ann Saudi Med 2009;29:105-9.

13. Bishara RA, Pasch AR, Lim LT, Meyer JP, Schuler JJ, Hall $\mathrm{RF} \mathrm{Jr}$, et al. Improved results in the treatment of civilian vascular injuries associated with fractures and dislocations. J Vasc Surg 1986;3:707-11.

14. Engin M, Aydın H. Evaluation of traumatic extremity vascular injuries in surviving and non-surviving patients. Turk J Vasc Surg 2019;28:95-100.

15. Percival TJ, White JM, Ricci MA. Compartment syndrome in the setting of vascular injury. Perspect Vasc Surg Endovasc Ther 2011;23:119-24.

16. Burma O, Uysal A, Özsin KK, Tok R, Köksal H, Rahman A. Periferik damar yaralanmalarında cerrahi deneyimimiz: 175 olgunun değerlendirilmesi. Turk Gogus Kalp Dama 2005;13:252-4.

17. Salimi J, Karbakhsh M, Zarei MR. Vascular injuries in Tehran: A review of 123 cases. Acta Medica Iranica 2006;44:333-40.

18. Akça B. Management of war-related vascular injuries: A civilian surgeon experience in the treatment of war casualties at a secondary care hospital. RJMM 2019;122:3-29.

19. Hanedan MO, Ketenciler S, Ercişli AM, Çiftçi B, Duman Z, Polat M. Civil war surgical experience: Gun shot or shell fragment injuries. Turk J Vasc Surg 2014;23:1-4. 